\title{
Predictors of timely diagnostic follow-up after an abnormal Pap test among Hispanic women seeking care in El Paso, Texas
}

\author{
Thelma Carrillo ${ }^{1 \dagger}$, Jane R. Montealegre ${ }^{2,3 \dagger}$, Christina G. Bracamontes ${ }^{1}$, Michael E. Scheurer ${ }^{2,3}$, Michele Follen ${ }^{1,4}$
} and Zuber D. Mulla ${ }^{1,5^{*}}$ (D)

\begin{abstract}
Background: Diagnostic follow-up of women with an abnormal Pap test is necessary to resolve the risk developing cervical cancer. The purpose of this study is to describe patient characteristics associated with timely receipt of a diagnostic colposcopy after an abnormal Pap test among Hispanic women in El Paso, a Texas-Mexico border city.

Methods: We conducted a retrospective chart review of Hispanic patients seen at an academic colposcopy clinic following an abnormal Pap test. An optimal diagnostic interval to colposcopy was based on a National Breast and Cervical Cancer Early Detection Program (NBCCEDP) quality indicator and was defined as receipt of colposcopy within 90 days or less from the date of an abnormal Pap test. Risk ratios (RR) were calculated by building a generalized linear model fit using a Poisson distribution, log link, and robust variance.

Results: Overall, 177 of the 270 women (65.6\%) received follow-up within an optimal diagnostic interval. After adjusting for other variables in the model, women who were 30 years of age or older were $32 \%$ more likely to have an optimal interval than younger women (adjusted $R R=1.32, P<0.01$ ). High school graduates were less likely than more educated women to have an optimal interval (adjusted $R R=0.68, P<0.01$ ). Participation in the NBCCEDP was not associated with receipt of follow-up within an optimal diagnostic interval.

Conclusions: Compared with women with greater educational attainment, high school graduates were less likely to receive follow-up within an optimal diagnostic interval, as were younger ( $<30$ years) women compared with older women. Participation in the NBCCEDP was not associated with receipt of care within an optimal diagnostic interval.
\end{abstract}

Keywords: Inequity, Colposcopy, Adherence, Cervical cancer, Hispanic, Texas-mexico border

\section{Background}

Cervical cancer incidence and mortality have decreased dramatically since widespread screening with the Papanicolaou test became available in the 1940s [1]. However, in

\footnotetext{
*Correspondence: zuber.mulla@ttuhsc.edu

†Thelma Carrillo and Jane R. Montealegre equally contributed to this work

${ }^{1}$ Department of Obstetrics and Gynecology, Paul L. Foster School

of Medicine, Texas Tech University Health Sciences Center El Paso, El Paso,

TX, USA

Full list of author information is available at the end of the article
}

2015 there were an estimated 12,900 new cases of invasive cervical cancer and 4,100 deaths in the United States (U.S.) [2]. Cervical cancer incidence and mortality are highest among minority women, specifically among African-American and Hispanic women [3], with respective incidence and mortality rates of 9.0 and 4.0 per 100,000 among African Americans and 9.5 and 2.5 per 100,000 among Hispanic women compared with 7.1 and 2.1 per 100,000 among non-Hispanic Whites [2, 4, 5]. In 2013, Hispanic women in Texas had the second highest cervical cancer mortality rates among Hispanic women in the 
nation, with mortality rates of 3.1 per 100,000 [5]. The cervical cancer mortality rates among women along the Texas-Mexico border are reported to be even higher than for women living in non-border counties in Texas. In the years 2002-2006, Hispanic women along the Texas-Mexico border had a cervical cancer mortality rate of 4.6 per 100,000 compared with 2.5 per 100,000 in non-Hispanic White women living in non-border counties [6]. Unsurprisingly, women along the border are less likely to report a recent Pap test compared with women in non-border counties in Texas, $61.7 \%$ vs. $75.7 \%$ [7] and are substantially less likely to have health insurance, $52.6 \%$ vs. $73.7 \%$ [7].

While racial/ethnic disparities in cervical cancer incidence are primarily due to decreased access and utilization of screening, lower rates of diagnostic and therapeutic follow-up among Hispanic and African American women also contribute to higher cervical cancer mortality among these groups [8-10]. Recent studies suggest that 13 to $40 \%$ of cervical cancer diagnoses result from lack of follow-up among women with an abnormal screening test [11-13]. Diagnostic follow-up typically involves a colposcopy with biopsy of areas with apparent abnormalities [14] and treatment recommendations are based on these results. While there are no data to clearly define a specific interval in which receipt of diagnostic follow-up optimally increases survival, longer time to treatment has been shown to result in later stage disease and, consequently, poorer survival [15].

Barriers to timely diagnostic follow-up are complex and include inadequate access to healthcare services, communication barriers between patients and providers, inexperience navigating the health care system, and psychological distress [16-18]. The National Breast and Cervical Cancer Early Detection Program (NBCCEDP), which provides low-income, uninsured, and underserved women access to timely breast and cervical cancer screening and diagnostic services, aims to address these barriers through evidence-based interventions at multiple levels of the social ecological model [19-21].

In this analysis, we examine the characteristics of predominantly low-income Hispanic women living along the Texas-Mexico border who received timely followup diagnostic care after receiving their abnormal Pap smear results. Specifically, we examined characteristics of women who obtained their colposcopy exam within the 90 day follow-up interval established by the NBCCEDP as a quality indicator. Given that Hispanic women along the U.S-Mexico border are among the demographic groups with the highest cervical cancer incidence and mortality rates in the U.S., identifying characteristics associated receiving timely follow-up is crucial for the development of interventions to deliver timely care to this population.

\section{Methods \\ Participants}

This was a retrospective cohort study of women presenting for diagnostic colposcopy at an academic healthcare center (Texas Tech University Health Sciences Center, TTUHSC) in El Paso, Texas between 2012 and 2014 following their receipt of an abnormal Pap test result. TTUHSC receives NBCCEDP funding distributed from the state of Texas and since 2007 has provided care to over 2,700 El Paso residents enrolled in the NBCCEDP program. A woman who is between 21 and 64 years of age who has an intact uterus and does not have health insurance or whose health insurance carrier does not cover Pap testing is eligible for free cervical cancer screening via the NBCCEDP if her family income is $\leq 250 \%$ of the federal poverty level [21]. Some states, however, use a different poverty threshold namely $\leq 200 \%$ of the federal poverty level [21].

Participants in this study were those taking part in a larger National Institutes of Health-sponsored clinical trial to evaluate emerging optical technologies for diagnosis of cervical dysplasia [22, 23]. The protocol of the parent study (Development and Application of a Multispectral Digital Colposcope and Probe Algorithm for Detection of Cervical Intraepithelial Neoplasia) was reviewed and approved by the TTUHSC Institutional Review Board (IRB) for the Protection of Human Subjects (IRB \# E12117). A written informed consent was obtained from each of the study subjects. The current project was a quality assurance/quality improvement investigation and hence did not require IRB approval. Of the 329 participants enrolled in the trial, 13 were excluded because they were not of Hispanic ethnicity or had an unknown Hispanic ethnicity status. Another 46 were excluded because they had missing values for one or more of the variables that were included in the multivariate analysis. These exclusions resulted in a final sample size of 270 participants.

\section{Procedure}

Medical records of trial participants were reviewed to ascertain their cervical cytology history, particularly the date of their last Pap test, the result of their last Pap test, and the date that they attended the colposcopy exam. A questionnaire regarding sociodemographic and risk factor characteristics was administered at the clinic by trained, bilingual/bicultural interviewers prior to the procedure. 


\section{Measures}

An optimal interval between an abnormal Pap test and colposcopy was defined as receiving a colposcopy within $\leq 90$ days of an abnormal Pap test result [20]. Subjects whose interval between the date of their abnormal Pap smear and the date of their colposcopy was 90 days or less were classified as having an optimal interval. Subjects whose interval was greater than 90 days were classified as not having an optimal interval.

Sociodemographic characteristics included age ( $\geq 30$ years versus $<30$ years), education less than high school, high school graduate, greater than high school, place of birth (U.S. vs. other country), participation in the NBCCEDP, and acculturation. In regards to educational attainment, subjects were asked, "What is the highest level of education you have completed?".

Acculturation was measured by the Marín Short Acculturation Scale for Hispanics (SASH) [24]. Study subjects answered four questions concerning what language(s) they read, speak, and think in. The response for each of the four questions ranged from 1 to 5 with the following coding scheme: $1=$ Only Spanish, $2=$ Spanish better than English, 3=Both Equally, $4=$ English better than Spanish, $5=$ Only English. The responses provided by the subjects was averaged across the four items. Subjects whose mean SASH score was greater than 2.99 were classified as "more acculturated" while those with a mean SASH score of 2.99 or less were classified as "less acculturated." Hispanic ethnicity was assessed with the question, "Are you of Hispanic, Latino or Spanish origin?" and categorized as No-Not of Hispanic Latino or Spanish origin, YesMexican-Mexican American-Chicano, Yes-Puerto Rican, Yes-Cuban, Yes-another Hispanic-Latino or Spanish origin, Don't Know, or Refused.

Smoking status was used as a surrogate measure of risk-taking behaviors given the findings of previous investigators [25, 26]. For example, Escobedo et al. [26] studied a nationally representative sample of adolescents from the United States and found that cigarette smoking was correlated with having multiple sexual partners among Hispanic females. Participants in our study were classified as smokers if they had smoked 100 or more cigarettes during their entire life. Clinical characteristics included the result of the last Pap test results, which was dichotomized as high-grade result versus normal or lowgrade result.

\section{Statistical analysis}

Data were analyzed using SAS 9.3 software (SAS Institute, Inc., Cary, North Carolina). The outcome of interest was an optimal diagnostic interval. Frequencies and Pearson's chi-square tests were used to compare demographic, epidemiologic, and clinical characteristics among participants who had an optimal diagnostic interval and those who did not. The following variables (detailed above) were deemed to be of clinical and/or epidemiological importance and hence were entered in our regression models: age, educational level, Hispanic acculturation status, place of birth, participation in the NBCCEDP, smoking status, and a high-grade result on the last Pap test.

Our initial attempt at a multivariable analysis involved fitting a log-binomial regression model using the GENMOD Procedure and specifying a binomial distribution with a log link; however, this model did not converge. As an alternative, Poisson regression with a robust variance was used to examine factors that were associated with having an optimal diagnostic interval [27]. Collinearity among the predictor variables was not detected using a logistic regression model. Adjusted risk ratios (RR) from the multiple Poisson regression model were reported along with 95\% confidence intervals (CI) and p-values. Associations with a p-value $\leq 0.05$ were considered statistically significant.

\section{Results}

A total of 270 Hispanic women were included in the analysis. The majority of these women (98.5\%) identified themselves as being of Mexican, Mexican-American, or Chicano origin while the remaining $1.5 \%$ were Puerto Rican or of another Hispanic, Latino, or Spanish origin. Additional characteristics of the sample are reported in Table 1 . Approximately $66 \%$ of the subjects had an optimal interval ( $\leq 90$ days) between the date of their abnormal Pap smear and the date the colposcopy was performed. The median number of days from the abnormal Pap to colposcopy was 59 days (range 9 to 90 days) among women who received care in the optimal interval and 148 days (range 91-516 days) among those who received follow-up care after 90 days. A total of 13 women had both a high-grade lesion and a sub-optimal interval (>90 days), and none of these women were diagnosed with cancer (data not shown). Of the 177 subjects who had an optimal interval, $60.5 \%$ were $\geq 30$ years of age, and of the 93 subjects who did not have an optimal interval, $40.0 \%$ were $\geq 30$ years of age $(P=0.001)$. The prevalence of being more acculturated (versus less acculturated) was $41.2 \%$ in the optimal interval group and $57.0 \%$ in the sub-optimal group $(P=0.01)$. Women who had an optimal interval were less likely to be born in the United States than subjects who did not have an optimal interval: $46.3 \%$ vs. $59.1 \%(P=0.045)$.

Adjusted RRs are presented in Table 2. After adjusting for other variables in the model, having an optimal interval to colposcopy was associated with age and education. Women who were 30 years of age or older were 
Table 1 Characteristics of 270 Hispanic women with an abnormal Pap smear, categorized by the duration of their diagnostic interval

\begin{tabular}{|c|c|c|c|}
\hline Characteristic & $\begin{array}{l}\text { Had an optimal interval } \\
N=177 \\
\text { Number (\%) }\end{array}$ & $\begin{array}{l}\text { Did not have an optimal interval } \\
\mathrm{N}=93 \\
\text { Number (\%) }\end{array}$ & $P$ \\
\hline \multicolumn{4}{|l|}{ Demographic and epidemiologic } \\
\hline Age $\geq 30$ years & $107(60.5)$ & $37(40.0)$ & 0.001 \\
\hline Educational level & & & 0.17 \\
\hline Less than high school & $48(27.1)$ & $21(22.6)$ & \\
\hline High school graduate & $32(18.1)$ & $26(28.0)$ & \\
\hline Greater than high school & $97(54.8)$ & $46(49.5)$ & \\
\hline More acculturated (vs. less) ${ }^{b}$ & $73(41.2)$ & $53(57.0)$ & 0.01 \\
\hline Place of birth & & & 0.045 \\
\hline United States & $82(46.3)$ & $55(59.1)$ & \\
\hline Outside of the United States & $95(53.7)$ & $38(40.9)$ & \\
\hline $\begin{array}{l}\text { Participant in the National Breast and Cervical Cancer Early } \\
\text { Detection Program }\end{array}$ & $88(49.7)$ & $50(53.8)$ & 0.53 \\
\hline Smoked $\geq 100$ cigarettes in entire life & $39(22.0)$ & $27(29.0)$ & 0.20 \\
\hline \multicolumn{4}{|l|}{ Clinical and clinico-pathologic } \\
\hline High-grade result on Pap smear & $33(18.6)$ & $13(14.0)$ & 0.33 \\
\hline
\end{tabular}

a Defined as 90 days or less

b As measured by the Marín Short Acculturation Scale for Hispanics (SASH)

Table 2 Adjusted ${ }^{\text {a }}$ risk ratios (RR) for an optimal interval ( $\leq 90$ days) between the date of an abnormal Pap smear and date of colposcopy in $\mathbf{2 7 0}$ Hispanic women

\begin{tabular}{|c|c|c|c|}
\hline Variable & RR & $\begin{array}{l}95 \% \\
\text { confidence } \\
\text { interval }\end{array}$ & $P$ \\
\hline \multicolumn{4}{|l|}{ Demographic and epidemiologic } \\
\hline Age $\geq 30$ years (vs. age $<30$ years) & 1.32 & $1.09-1.61$ & 0.005 \\
\hline \multicolumn{4}{|l|}{ Educational level } \\
\hline Less than high school & 0.84 & $0.67-1.04$ & 0.11 \\
\hline High school graduate & 0.68 & $0.53-0.88$ & 0.004 \\
\hline Greater than high school & 1 & (Referent) & - \\
\hline More acculturated (vs. less acculturated) & 0.82 & $0.65-1.02$ & 0.08 \\
\hline \multicolumn{4}{|l|}{ Place of birth } \\
\hline United States & 0.93 & $0.75-1.15$ & 0.51 \\
\hline Outside of the United States & 1 & (Referent) & - \\
\hline $\begin{array}{l}\text { Participant in the National Breast and Cervi- } \\
\text { cal Cancer Early Detection Program (vs. not } \\
\text { a participant) }\end{array}$ & 1.03 & $0.87-1.23$ & 0.74 \\
\hline $\begin{array}{l}\text { Smoked } \geq 100 \text { cigarettes in entire life } \\
(\text { vs. }<100)\end{array}$ & 0.86 & $0.69-1.07$ & 0.19 \\
\hline \multicolumn{4}{|l|}{ Clinical and clinico-pathologic } \\
\hline $\begin{array}{l}\text { High-grade result on Pap smear (vs. other } \\
\text { result) }\end{array}$ & 1.13 & $0.92-1.39$ & 0.25 \\
\hline
\end{tabular}

RRs are from a Poisson regression model with robust variance estimation

${ }^{a}$ Each RR is adjusted for the remaining variables found in the table
$32 \%$ more likely to have an optimal interval than younger women. High school graduates were $32 \%$ less likely than those with a higher education to have an optimal interval $(\mathrm{RR}=0.68,95 \% \mathrm{CI}: 0.53-0.88)$. The association between acculturation and having an optimal interval that was detected in the univariate analysis (Table 1) was not observed after adjusting for the remaining six predictor variables. Participation in the NBCCEDP program was not associated with having an optimal interval.

\section{Discussion}

One of the major factors contributing to cervical cancer incidence in our and other medically underserved populations is non-receipt or untimely receipt of diagnostic and therapeutic follow-up after an abnormal Pap test [8-10]. In our sample, about $66 \%$ of patients had an optimal diagnostic interval as defined by the NBCCEDP. In El Paso, NBCCEDP patients receive patient navigation, a service that has been shown to improve timely follow-up among medically underserved women [28]. However, among cases in our analysis, NBCCEDP status was not associated with receipt of care within an optimal diagnostic interval. The reason for this null association requires further investigation. We feel that multiple factors could impact the length of the diagnostic interval independent of funding status including the reluctance of patients to undergo colposcopy, lack of transportation [29], variations in provider practice patterns, and issues surrounding the scheduling of appointments. 
A brief discussion of the cost of a colposcopy is merited at this point. While our NBCCEDP-funded patients were not charged for undergoing colposcopy, patients who paid cash (self-pay patients) for a colposcopy were billed USD 369 by our institution during fiscal year 2014. Selfpay patients were charged USD 454 for a colposcopy with biopsy (biopsies) during fiscal year 2014.

A recent national-level analysis of NBCCEDP data indicated that in $2009,71 \%$ of NBCCEDP patients met a 60 -day diagnostic interval, the performance measure at the time, with a larger proportion of the programs $(>80 \%)$ meeting the current 90-day diagnostic interval during the period 2003-2009 [20]. However, the same study found racial and ethnic disparities in diagnostic intervals, with the longest wait times for diagnosis after a screeningdetected abnormality among black and Hispanic women [20]. The median diagnostic intervals in that study were 47 days in White women, 48 days in Asian women, and 50 days in both Black and Hispanic women [20]. The barriers that limit timely diagnostic resolution among Hispanic NBCCEDP participants nationwide are likely similar to those experienced in El Paso and further study is needed to elucidate them.

Being born outside the U.S. was also hypothesized to be associated with a longer interval to diagnostic colposcopy given that immigrants often face barriers to healthcare access, including lack of insurance, lack of awareness of available resources, and linguistic and cultural barriers [29]. However, while US-born women in our sample were more likely than foreign-born women to exceed an optimal diagnostic interval, this association did not remain statistically significant after controlling for age and other variables.

We did find a significant association between both age and education and attendance to colposcopy within an optimal diagnostic interval. Women who were $\geq 30$ years of age were $32 \%$ more likely than younger women to have an optimal interval between the time of their abnormal Pap smear and the performance of the colposcopy. This finding is consistent with other studies that have also reported a higher likelihood to default from follow-up diagnostic care among younger women [12,30]. Younger women are significantly less likely than older women to have health insurance coverage, leaving them vulnerable to high out-of-pocket expenses for medical procedures such as colposcopy [31]. Women under 30 years may also face increased distress barriers compared with older women [32], particularly related to potential reproductive consequences such as the loss of fertility which may be a consequence of the treatment for cervical cancer [33, 34].

In regard to education, we found that timely attendance to colposcopy was more likely among Hispanic women with more than a high school education compared with those with a high school education only. Interestingly, the likelihood of timely attendance to colposcopy was similar among women with less than a high school education compared with those with a post-high school education. While Sharp et al. reported that women with post-high school education were more likely to attend for colposcopy [35], education in their study was dichotomized as having post-high school education versus not. Our results suggest that in populations with a high proportion of individuals with less than a high school education, such as border Hispanic women, the association between education and attendance for diagnostic follow-up may be more nuanced.

The findings of this study should be interpreted within the context of its limitations. Because women were recruited at a colposcopy clinic, our study sample only includes women who ultimately attended for colposcopy. Inclusion of non-attenders in future studies may better elucidate the role that patient characteristics play in predicting timely follow-up. We did not assess the role of other individual-level barriers such as knowledge about cervical cancer prevention, language barriers impeding understanding and communication with health care providers, inexperience in navigating the health care system, and lack of health insurance. Similarly, we were unable to elucidate social and cultural impediments for the receipt of diagnostic care, such as fear of stigmatization and psychological fears, including fatalismo, or fatalistic fears which may impede individuals from seeking care [36, 37]. Despite these limitations, our results provide valuable data describing timeliness of cervical cancer diagnosis among a unique group of medically underserved Hispanic women. Clinicians should be aware of increased likelihood of non-attendance among younger women and those with a high school education only. Patient education efforts can focus on this group to reinforce the need for clinical follow-up. In 2016, 16.6\% of Texans did not have health insurance coverage [38]. In contrast, the prevalence of individuals without health insurance in the U.S. in 2016 was $8.6 \%$ [38]. Given the high proportion of persons living without health insurance in Texas, the NBCCEDP continues to be a relevant and important initiative.

Finally, research is needed to determine how grantees of NBCCEDP funds can better ensure timely screening, diagnostic and treatment care among eligible Hispanic women. Marlow and colleagues conducted a qualitative study (using six focus groups) to investigate barriers to cervical cancer screening among women 50 to 64 years of age in England [39]. Those authors identified several reasons why some women did not attend cervical cancer screening including embarrassment, discomfort, 
and a lack of an invitation letter (some participants had not received prompts to be screened from a healthcare professional) [39]. Holding focus groups of women of various ages and conducting key informant interviews of community health workers and health care providers in our region may aid us in identifying interventions that will decrease the interval between an abnormal Pap smear result and colposcopy.

\section{Abbreviations}

Cl: Confidence interval; NBCCEDP: National Breast and Cervical Cancer Early Detection Program; RR: Risk ratio; SASH: Short Acculturation Scale for Hispanics; US: United States.

\section{Acknowledgements}

The authors would like to express our gratitude to the women who participated in this study. The authors also thank Kayla Castañeda, RN, MSN, WHNPBC, AOCNP ${ }^{\circledR}$, for performing colposcopies, and Lisa Aguilar, LBSW, Director of Social Services in the Department of Obstetrics and Gynecology at Texas Tech University Health Sciences Center El Paso, for providing us with colposcopy billing information.

\section{Authors' contributions}

TC: Study design, data collection, and write up of the manuscript. JRM: Study design, data analysis, and write up of the manuscript. CGB: Study design, data collection, and write up of the manuscript. MES: Study design, write up of the manuscript. MF: Study design, data collection, and write up of the manuscript. ZDM: Study design, data analysis, and write up of the manuscript. All of the authors have read and approved the manuscript.

\section{Funding}

This work was supported in part by the following grant from the U.S. National Institutes of Health: Optical Technologies and Molecular Imaging for Cervical Neoplasia (3 P01 CA082710, Principal investigator: M. Follen). The National Institutes of Health did not play a role in the design and analysis of the current study and was not involved in the interpretation of the results or drafting of the manuscript.

\section{Availability of data and materials}

The dataset for the current study is available from the corresponding author upon receipt of a reasonable request.

\section{Ethics approval and consent to participate}

Administrative permissions were not required to access and use our study data. This project was a quality improvement investigation which used a deidentified dataset that was derived from a study that was previously approved by the Institutional Review Board (IRB) for the Protection of Human Subjects of the Texas Tech University Health Sciences Center El Paso. An application was submitted to our IRB on 16 December 2020. On 18 December 2020 our IRB issued a letter stating that they do not typically review quality improvement projects. Additionally, our IRB does not consider the analysis of a de-identified dataset to meet the definition of human subjects research.

\section{Consent for publication}

Not applicable.

\section{Competing interests}

The authors declare that they have no competing interests.

\section{Author details}

${ }^{1}$ Department of Obstetrics and Gynecology, Paul L. Foster School of Medicine, Texas Tech University Health Sciences Center El Paso, El Paso, TX, USA. ${ }^{2}$ Department of Pediatrics, Baylor College of Medicine, Houston, TX, USA.

${ }^{3}$ Dan L. Duncan Comprehensive Cancer Center, Baylor College of Medicine, Houston, TX, USA. ${ }^{4}$ Present Address: NYC Health + Hospitals| Kings County, Brooklyn, NY, USA. ${ }^{5}$ Office of Faculty Development (MSC 21007), Texas Tech
University Health Sciences Center El Paso, 5001 El Paso Drive, El Paso, TX 79905, USA.

Received: 9 April 2019 Accepted: 25 December 2020

Published online: 06 January 2021

\section{References}

1. Barnholtz-Sloan J, Patel N, Rollison D, Kortepeter K, MacKinnon J, Giuliano A. Incidence trends of invasive cervical cancer in the United States by combined race and ethnicity. Cancer Cause Control. 2009;20(7):1129-38.

2. Howlader NA, Krapcho M, Garshell J, et al. SEER cancer statistics review, 1975-2012. Bethesda, MD: National Cancer Institute; 2015.

3. Watson M, Saraiya M, Benard V, et al. Burden of cervical cancer in the United States, 1998-2003. Cancer. 2008;113(10 Suppl):2855-64.

4. Centers for Disease Control and Prevention (CDC). Invasive cervical cancer among Hispanic and non-Hispanic women-United States, 1992-1999. Morbid Mortal Wkly Rep. 2002;51(47):1067-70.

5. U.S. Cancer Statistics Working Group. United States Cancer Statistics: 1999-2013 Incidence and mortality web-based report. Atlata, GA: U.S. Department of Health and Human Services, Centers for Disease Control and Prevention and National Cancer Institute; 2015.

6. Risser DR, Mokry B, Bowcock C, Miller EA, Williams MA, Magid R, Garcia R. Cervical Cancer in Texas, 2010. Austin, TX: Texas Cancer Registry, Texas Department of State Health Services; Cancer Prevention Research Institute of Texas, November 2010.

7. Texas Department of State Health Services. Texas behavioral risk factor surveillance system. Austing, TX. 2014. http://healthdata.dshs.texas.gov. Accessed 20 Oct 2016.

8. Benard VB, Lawson HW, Eheman CR, Anderson C, Helsel W. Adherence to guidelines for follow-up of low-grade cytologic abnormalities among medically underserved women. Obst Gynecol. 2005;105(6):1323-8.

9. Engelstad LP, Stewart SL, Nguyen BH, et al. Abnormal Pap smear follow-up in a high-risk population. Cancer Epidemiol Biomarkers Prev. 2001;10(10):1015-20.

10. Jones BAND. Follow-up of abnormal gynecologic cytology: a College of American Pathologists Q-Probes study of 16132 cases from 306 laboratories. Arch Pathol Lab Med. 2000;124:665-71.

11. Leyden WA, Manos MM, Geiger AM, et al. Cervical cancer in women with comprehensive health care access: attributable factors in the screening process. J Natl Cancer Inst. 2005;97(9):675-83.

12. Peterson NB, Han J, Freund KM. Inadequate follow-up for abnormal Pap smears in an urban population. J Natl Med Assoc. 2003;95(9):825-32.

13. Pritham UA, Brigdon A, Jones M. Understanding factors related to women's adherence to colposcopy. Nurs Womens Health. 2014;18(5):402-12.

14. Saslow D, Solomon D, Lawson HW, Killackey M, Kulasingam S, Cain J, et al. American Cancer Society, American Society for Colposcopy and Cervical Pathology, and American Society for Clinical Pathology Screening Guidelines for the Prevention and Early Detection of Cervical Cancer. CA Canc J Clin. 2012;62(3):147-72.

15. Ashing-Giwa KT, Tejero JS, Kim J, Padilla GV, Kagawa-Singer M, Tucker MB, et al. Cervical cancer survivorship in a population based sample. Gynecol Oncol. 2009;112(2):358-64.

16. Yabroff KR, Lawrence WF, Clauser S, Davis WW, Brown ML. Burden of illness in cancer survivors: findings from a population-based national sample. J Natl Cancer Inst. 2004;96(17):1322-30.

17. Lerman C, Miller SM, Scarborough R, Hanjani P, Nolte S, Smith D. Adverse psychologic consequences of positive cytologic cervical screening. Am J Obst Gynecol. 1991;165(3):658-62.

18. Brooks SE, Gordon NJ, Keller SJ, Thomas SK, Chen TT, Moses G. Association of knowledge, anxiety, and fear with adherence to follow up for colposcopy. J Lower Genital Tract Dis. 2002;6(1):17-22.

19. Lee NC, Wong FL, Jamison PM, Jones SF, Galaska L, Brady KT, et al. Implementation of the National Breast and Cervical Cancer Early Detection Program: the beginning. Cancer. 2014;120(016):2540-8.

20. Benard VB, Howe W, Royalty J, Helsel W, Kammerer W, Richardson LC. Timeliness of cervical cancer diagnosis and initiation of treatment in the National Breast and Cervical Cancer Early Detection Program. J Womens Health. 2012;21(7):776-82. 
21. Tangka FK, O'Hara B, Gardner JG, Turner J, Royalty J, Shaw K, et al. Meeting the cervical cancer screening needs of underserved women: the National Breast and Cervical Cancer Early Detection Program, 2004-2006. Cancer Cause Control. 2010;21(7):1081-90.

22. Cardenas-Turanzas M, Nogueras-Gonzalez GM, Scheurer ME, AdlerStorthz K, Benedet JL, Beck JR, et al. The performance of human papillomavirus high-risk DNA testing in the screening and diagnostic settings. Cancer Epidemiol Biomarkers Prev. 2008;17(10):2865-71.

23. Buys TPH, Cantor SB, Guillaud M, Adler-Storthz K, Cox DD, Okolo C, et al. Optical technologies and molecular imaging for cervical neoplasia: a program project update. Gend Med. 2012;9(1 Suppl):S7-24.

24. Marín G, Sabogal F, VanOss MB, Otero-Sabogal R, Pérez-Stable EJ. Development of a short acculturation scale for Hispanics. Hisp J Behav Sci. 1987;9(2):183-205.

25. Ert E, Yechiam E, Arshavsky O. Smokers' decision making: more than mere risk taking. PLoS ONE. 2013;8(7):e68064.

26. Escobedo LG, Reddy M, DuRant RH. Relationship between cigarette smoking and health risk and problem behaviors among US adolescents. Arch Pediatr Adoles Med. 1997;151(1):66-71.

27. Spiegelman D, Hertzmark E. Easy SAS calculations for risk or prevalence ratios and differences. Am J Epidemiol. 2005;162(3):199-200.

28. Markossian TW, Darnell JS, Calhoun EA. Follow-up and timeliness after an abnormal cancer screening among underserved, urban women in a patient navigation program. Cancer Epidemiol Biomarkers Prev. 2012;21(10):1691-700

29. Montealegre JR, Selwyn BJ. Healthcare coverage and use among undocu mented Central American immigrant women in Houston, Texas. J Immigr Minor Health. 2014;16(2):204-10.

30. Ell K, Vourlekis B, Muderspach L, Nissly J, Padgett D, Pineda D, et al. Abnormal cervical screen follow-up among low-income Latinas: project SAFe. J Womens Health Gend Based Med. 2002;11(7):639-51.

31. Cohen RA, Bloom B. Access to and utilization of medical care for young adults ages 20-29 years: United States, 2008. NCHS Data Brief. 2010;29:1-8.
32. Hui SK, Miller SM, Wen KY, Fang Z, Li T, Buzaglo J, et al. Psychosocial barriers to follow-up adherence after an abnormal cervical cytology test result among low-income, inner-city women. J Prim Care Community Health. 2014;5(4):234-41

33. Beresford JMG. The Emotional Impact of Abnormal Pap Smears on Patients Referred for Colposcopy. J Gynecol Surg. 2009;2(2):83-7.

34. McDonald TW, Neutens JJ, Fischer LM, Jessee D. Impact of cervical intraepithelial neoplasia diagnosis and treatment on self-esteem and body image. Gynecol Oncol. 1989;34(3):345-9.

35. Sharp L, Cotton S, Thornton A, Gray N, Cruickshank M, Whynes D, et al. Who defaults from colposcopy? A multi-centre, population-based, prospective cohort study of predictors of non-attendance for follow-up among women with low-grade abnormal cervical cytology. Eur J Obst Gynecol Rep Biol. 2012;165(2):318-25.

36. Abraído-Lanza AF, Martins MC, Shelton RC, Flórez KR. Breast cancer screening among Dominican Latinas: a closer look at fatalism and other social and cultural factors. Health Educ Behav. 2015;42(5):633-41.

37. Fairchild R. Fatalism and health behaviors: Exploring the context for clinician-patient interactions. Ann Nurs Pract. 2015;2(4):1032.

38. Barnett JC, Berchick ER. Current population reports, P60-260, health insurance coverage in the United States: 2016. Washington, DC: U.S. Government Printing Office; 2017

39. Marlow L, McBride E, Varnes L, Waller J. Barriers to cervical screening among older women from hard-to-reach groups: a qualitative study in England. BMC Women's Health. 2019;19(1):38.

\section{Publisher's Note}

Springer Nature remains neutral with regard to jurisdictional claims in published maps and institutional affiliations.
Ready to submit your research? Choose BMC and benefit from:

- fast, convenient online submission

- thorough peer review by experienced researchers in your field

- rapid publication on acceptance

- support for research data, including large and complex data types

- gold Open Access which fosters wider collaboration and increased citations

- maximum visibility for your research: over $100 \mathrm{M}$ website views per year

At $\mathrm{BMC}$, research is always in progress.

Learn more biomedcentral.com/submissions 